\title{
Coronary artery disease and haemostatic variables in heterozygous familial hypercholesterolaemia
}

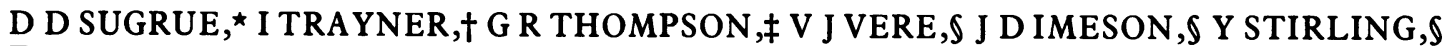 \\ $T$ W MEADES
}

From the $\star$ Department of Clinical Cardiology and the + Department of Chemical Pathology, Royal Postgraduate Medical School; the $¥ M R C$ Lipoprotein Team, Hammersmith Hospital, London; and the \$MRC Epidemiology and Medical Care Unit, Northwick Park Hospital, Harrow, Middlesex

SUMMARY Haemostatic variables were measured in 61 patients with heterozygous familial hypercholesterolaemia, 32 of whom had evidence of coronary heart disease. Age adjusted mean concentrations of plasma fibrinogen and factor VIII were significantly higher in these patients than in the 29 patients without coronary heart disease, but there were no significant differences in serum lipid concentrations between the two groups. Comparisons in 30 patients taking and not taking lipid lowering drugs showed lower values for low density lipoprotein cholesterol, high density lipoprotein cholesterol and antithrombin III, and a higher high density lipoprotein ratio while receiving treatment. The results suggest that hypercoagulability may play a role in the pathogenesis of coronary heart disease in patients with familial hypercholesterolaemia.

Premature coronary disease is a characteristic feature of heterozygous familial hypercholesterolaemia and up to $50 \%$ of male and $25 \%$ of female patients with familial hypercholesterolaemia develop symptoms of coronary ischaemia by the age of $50.1^{2}$ Increased concentrations of low density lipoprotein (LDL) play a major role in the pathogenesis of this premature atherosclerosis, but accelerated intravascular coagulation $^{3}$ and increased plasma fibrinogen concentrations have also been reported. ${ }^{45}$ Preliminary results from the Northwick Park heart study have shown an association between high plasma concentrations of factor VII, factor VIII, and fibrinogen and an increased risk of subsequent cardiovascular death. ${ }^{6}$ We have therefore measured these and other haemostatic variables in patients with familial hypercholesterolaemia with or without overt coronary heart disease and in addition have studied the effects of hypolipidaemic drugs on these variables.

\section{Patients and methods}

Sixty one patients (34 men, 27 women) aged 20-71 (mean 45) years with heterozygous familial hyper-

Requests for reprints to Dr G R Thompson, MRC Lipoprotein Team, Hammersmith Hospital, Ducane Road, London W12 0HS.

Accepted for publication 23 October 1984 cholesterolaemia were studied. Familial hypercholesterolaemia was defined as serum cholesterol concentration $>7.5 \mathrm{mmol} / \mathrm{l}$ in an adult or $>6.7 \mathrm{mmol} / 1$ in children under the age of 16 , together with tendon xanthomata or with hypercholesterolaemia plus tendon xanthomata or hypercholesterolaemia plus premature coronary disease (before the age of 60 ) in a first degree relative. Tendon xanthomata were present in $57 \%$ of patients. Most patients had a type IIa phenotype, but seven had raised serum triglyceride concentrations $(>2 \mathrm{mmol} / \mathrm{l})$ and a type IIb phenotype. All patients were receiving a low cholesterol diet, four had had a partial ileal bypass, and 44 were taking hypolipidaemic drugs (cholestyramine 17, probucol 8, clofibrate 6 , neomycin 1 , cholestyramine and clofibrate 6 , cholestyramine and neomycin 6 ). The presence of significant coronary disease was defined on the basis of one or more of the following: a reduction of $\geqslant 50 \%$ in the luminal diameter of any major coronary artery when seen in two projections at coronary arteriography which was performed where there was a clinical indication; the presence of angina or a positive 16 lead exercise precordial map 7 ; and electrocardiographic evidence of previous myocardial infarction. ${ }^{8}$

Coronary arteriograms were reviewed by two observers and assigned a score designed to denote the severity of disease based on the following criteria: 1 , significant strictures $(>50 \%$ reduction in luminal 
diameter seen in two projections) affecting a single vessel; 2, left main stem disease; 3 complete occlusion of the right coronary, the left anterior descending, or the left circumflex arteries.

Blood was taken from an antecubital vein between 0900 and 1200 hours after an overnight fast. Blood for assay of clotting factors was centrifuged at room temperature and the plasma stored in liquid nitrogen for subsequent assay. 9 Fibrinogen and biological activity of factors II, VII, VIII, and X and antithrombin III were measured by methods described elsewhere.910 Serum triglyceride concentrations were estimated enzymatically, ${ }^{11}$ and total cholesterol by an automated Leibermann-Burchard method.12 High density lipoprotein (HDL) cholesterol was measured by the heparin-manganese precipitation technique ${ }^{13}$ and the HDL ratio was calculated as $\mathrm{HDL} /$ total -HDL cholesterol. LDL cholesterol was estimated as described by Friedewald et al. ${ }^{14}$ In 28 patients measurements were repeated 5-10 weeks after hypolipidaemic drugs had been withdrawn $(n=22)$ or after previously untreated patients had started drug treatment $(n=6)$. Seventeen patients were taking cholestyramine (Questran) in a dose of $16 \mathrm{~g}$ daily, either alone or in combination with neomycin $2 \mathrm{~g}$ daily or clofibrate $\mathbf{2} \mathrm{g}$ daily, seven were taking probucol $1 \mathrm{~g}$ daily, and four clofibrate $2 \mathrm{~g}$ daily.

In the analyses comparing patients with and without coronary disease by unpaired $t$ tests, mean values were adjusted to age 50 years using coefficients derived from multiple regression analyses of each coagulation or biochemical variable on coronary disease (present or absent), sex, and age. Data on treatment effects were analysed by paired $t$ tests.

\section{Results}

A total of 32 patients (17 men and 15 women) (mean age 50.8, range 28-71 years) were identified as having coronary heart disease. This diagnosis was made on the following grounds: electrocardiographic evidence of myocardial infarction (5); coronary arteriographic abnormalities without infarct (6); coronary arteriographic abnormalities and infarct (10); and angina or a positive exercise precordial map or both (11). Seven patients had had previous coronary artery bypass surgery. The 29 patients without coronary disease, of whom 17 were men and 12 women, were younger than those with coronary disease (mean age 38.4 , range $20-59$ years).

There were no significant differences in any lipid variables between the two groups but mean concentrations of fibrinogen and factor VIII were significantly higher in the patients with coronary disease than in those without (Table 1). To see whether either of these differences could be accounted for by associations between factor VIII or fibrinogen and lipids, values for cholesterol, triglycerides, and HDL were included in further regression analyses as explanatory variables. The results did not differ materially from those shown in Table 1.

Untreated patients and those in whom hypolipidaemic drugs had been temporarily withdrawn had significantly higher LDL and HDL cholesterol concentrations and a lower HDL ratio compared with the treated state. Antithrombin III was significantly higher in patients not receiving treatment $(90 \%$ vs $82 \%, p<0.02)$, but none of the other haemostatic variables showed any significant difference (Table 2). Table 3 shows the effects of individual drug regimens. The small number of patients in each group precludes detailed statistical analysis, but the decrease in antithrombin III concentrations appeared to be greatest in patients taking probucol.

Coronary arteriograms were performed in 16 patients (13 men, three women, mean age 44 years). Angiographic scores ranged from 1 to 9 . The correlation between angiographic score and factor VIII was $-0.27(p=0.33)$ and for fibrinogen $-0.10(p=0.73)$.

\section{Discussion}

Premature and angiographically severe coronary dis-

Table 1 Age adjusted plasma lipid and lipoprotein concentrations and haemostatic variables in patients with familial hypercholesterolaemia with and without coromary heart disease (CHD). Values are mean (SD)

\begin{tabular}{llll}
\hline & With CHD $(\boldsymbol{n}=32)$ & Without $C H D(n=29)$ & $p$ value \\
\hline Fibrinogen (g/l) & $3.28(1.00)$ & $2.84(0.60)$ & 0.04 \\
Factor II (\%) & $107(30)$ & $117(22)$ & 0.18 \\
Factor VII (\%) & $123(48)$ & $122(39)$ & 0.92 \\
Factor VIII (\%) & $136(70)$ & $102(34)$ & 0.02 \\
Factor X (\%) & $87(25)$ & $81(16)$ & 0.30 \\
Antithrombin III (\%) & $82(17)$ & $86(20)$ & 0.37 \\
Total cholesterol (mmol//) & $8.23(1.88)$ & $8.00(1.41)$ & 0.59 \\
LDL cholesterol (mmol//) & $6.49(1.81)$ & $6.35(1.55)$ & 0.74 \\
HDL cholesterol (mmol/) & $0.99(0.32)$ & $1.03(0.38)$ & 0.65 \\
HDL ratio & $0.156(0.082)$ & $0.166(0.093)$ & 0.66 \\
Triglyceride (mmol//) & $1.59(0.75)$ & $1.49(0.59)$ & 0.62 \\
\hline
\end{tabular}

Conversion: SI to waditional units—cholesterol: $1 \mathrm{mmol} / 1 \approx 38.6 \mathrm{mg} / \mathrm{dl}$; triglyceride: $1 \mathrm{mmol} / \mathrm{2} \approx 88.5 \mathrm{mg} / \mathrm{dl}$. 
Table 2 Effect of treatment on lipid concentrations and haemostatic variables in 30 patients with familial hypercholesterolaemia. Figures are mean values

\begin{tabular}{lllll}
\hline & With treatment & Without treatment & SD of difference & $p$ value \\
\hline Fibrinogen (g/l) & 3.05 & 3.10 & 0.69 & 0.65 \\
Factor II (\%) & 111 & 120 & 30 & 0.12 \\
Factor VII (\%) & 119 & 115 & 27 & 0.44 \\
Factor VIII (\%) & 122 & 124 & 35 & 0.75 \\
Factor X (\%) & 83 & 88 & 21 & 0.25 \\
Antithrombin III (\%) & 82 & 90 & 19 & 0.02 \\
LDL cholesterol (mmol//) & 6.45 & 7.89 & 1.04 & 0.0001 \\
HDL cholesterol (mmol/) & 0.98 & 1.06 & 0.18 & 0.02 \\
HDL ratio & 0.151 & 0.129 & 0.052 & 0.92 \\
Triglyceride (mmol/l) & 1.79 & 1.79 & 0.36 & \\
\hline
\end{tabular}

$S D$, standard deviation.

Comversion: SI to traditional units-cholesterol: $1 \mathrm{mmol} / \approx \approx 38.6 \mathrm{mg} / \mathrm{dl}$; triglyceride: $1 \mathrm{mmol} / \approx 88.5 \mathrm{mg} / \mathrm{dl}$.

Table 3 Mean changes (SD) in lipid concentrations and haemostatic variables in 28 patients with familial hypercholesterolaemia taking various drugs

\begin{tabular}{|c|c|c|c|c|c|}
\hline & $\begin{array}{l}\text { Cholestyramine } \\
(n=10)\end{array}$ & $\begin{array}{l}\text { Cholestyramine } \\
\text { and neomycin } \\
(n=4)\end{array}$ & $\begin{array}{l}\text { Cholestyramine } \\
\text { and clofibrate } \\
(n=3)\end{array}$ & $\begin{array}{l}\text { Clofibrate } \\
(n=4)\end{array}$ & $\begin{array}{l}\text { Probucol } \\
(n=7)\end{array}$ \\
\hline $\begin{array}{l}\text { Fibrinogen (g/l) } \\
\text { Factor II }(\%) \\
\text { Factor VII (\%) } \\
\text { Factor VIII (\%) } \\
\text { Factor X (\%) } \\
\text { Antithrombin III (\%) } \\
\text { LDL cholesterol (mmol//) } \\
\text { HDL cholesterol (mmol/l) } \\
\text { HDL ratio } \\
\text { Triglyceride (mmol/l) }\end{array}$ & $\begin{array}{l}+0.19(0.79) \\
-18(42) \\
+2(40) \\
-15(29) \\
+2(30) \\
-7(22) \\
-1.47(1.51) \\
+0.01(0.13) \\
+0.05 \\
-0.71(2.47)\end{array}$ & $\begin{array}{l}-0.44(0.92) \\
-20(34) \\
-6(20) \\
+13(30) \\
-20(24) \\
-9(14) \\
-3.37(2.32) \\
-0.14(0.13) \\
+0.04 \\
+0.08(0.79)\end{array}$ & $\begin{array}{l}-0.07(0.32) \\
+11(13) \\
+22(22) \\
+35(48) \\
+4(8) \\
+3(13) \\
-1.70(0.24) \\
0.00 \\
+0.04 \\
-0.07(0.12)\end{array}$ & $\begin{array}{l}-0.01(0.59) \\
+9(7) \\
+10(13) \\
-5(24) \\
-10(13) \\
-4(13) \\
-1.16(1.06) \\
-0.14(0.21) \\
-0.02 \\
+1.85(2.86)\end{array}$ & $\begin{array}{l}-0.10(0.69) \\
-9(14) \\
+4(18) \\
-4(41) \\
+2(13) \\
-12(13) \\
-0.51(1.02) \\
-0.04(0.29) \\
0.00 \\
-0.01(0.80)\end{array}$ \\
\hline
\end{tabular}

$\star$ Questran.

Conversion: SI to traditional units—cholesterol: $1 \mathrm{mmol} / \approx \approx 38.6 \mathrm{mg} / \mathrm{dl}$; triglyceride: $1 \mathrm{mmol} / \mathrm{l} \approx 88.5 \mathrm{mg} / \mathrm{dl}$.

ease is common in heterozygous familial hypercholesterolaemia. ${ }^{12} 15$ This premature disease is not solely a function of LDL concentrations; additional risk factors include a decrease in HDL cholesterol and in the HDL:LDL ratio, ${ }^{16} 17$ smoking, ${ }^{18}$ and a family history of premature death. ${ }^{19}$ In addition, abnormalities in haemostatic function have been found both in familial hypercholesterolaemia and in men who later died of coronary heart disease. Thus the Northwick Park heart study found that plasma concentrations of factor VII, VIII, and fibrinogen as well as serum cholesterol concentrations were significantly higher at entry to the study in the $\mathbf{2 7}$ men who died of cardiovascular disease (mostly coronary heart disease) than in the 1461 survivors. ${ }^{6}$ Lowe et al found significantly raised fibrinogen concentrations in patients with familial hypercholesterolaemia, ${ }^{5}$ whereas Carvalho and Lees found evidence for activation of the intrinsic coagulation system (low prekallikrein and kallikrein inhibitor values and increased concentrations of soluble fibrin complexes). ${ }^{3}$ Lowe et al also examined the relation between plasma fibrinogen concentrations, platelet aggregates, and coronary disease in familial hypercholesterolaemia. 5 They showed increased fibrinogen concentrations and increased numbers of platelet aggregates from the age of 15 onwards, which they suggested might be markers of the underlying atherosclerosis to which these patients are so susceptible. They failed to show any correlation between the serum cholesterol concentrations and the coagulation abnormalities, which were as evident in patients taking effective cholesterol lowering drugs as in untreated individuals.

Hypercoagulability could well play a role in the development of coronary disease since thrombotic coronary occlusion occurs in the majority of patients in the early stages of myocardial infarction. ${ }^{20} \mathrm{High}$ fibrinogen concentrations increase blood viscosity, ${ }^{21}$ and increased viscosity may in turn impair blood flow, ${ }^{22}$ thus predisposing to thrombosis. Small deposits of fibrin have been found on or just beneath the endothelium even in neonates ${ }^{23}$ with a rapid increase in prevalence with increasing age. Smith and Staples found high concentrations of fibrinogen in atherosclerotic lesions from human aortic intima along with variable concentrations of factor VIII. ${ }^{24}$ It remains debatable whether such abnormalities of haemostatic function play an initiating role in the pathogenesis of coronary disease or whether, as has been suggested, 6 they are simply markers of premature vascular disease and represent responses to arterial injury. 
Previous studies have shown that lipid lowering diets and clofibrate tend to exert what would be expected to be a beneficial effect on haemostatic variables in patients with hypertriglyceridaemia. $25-27$ Nevertheless, the slight but significant decrease in the thrombin inhibitor antithrombin III observed in our patients with familial hypercholesterolaemia while taking lipid lowering drugs is potentially adverse; this effect was most pronounced in patients taking probucol or cholestyramine in combination with neomycin, in whom a theoretically undesirable decrease in HDL cholesterol was also observed. Probucol and neomycin are each known to reduce both LDL and HDL, ${ }^{28} 29$ but the decrease in HDL cholesterol was not seen in patients taking cholestyramine alone. The major effect of lipid lowering treatment overall was to decrease LDL cholesterol by $18 \%$, which resulted in a significant increase in the HDL ratio. Comparable changes in a similar group of patients with hypercholesterolaemia treated with diet and cholestyramine for five years were recently shown to be associated with a reduction in the rate of progression of their coronary disease on angiography. ${ }^{30} 31$

\section{DDS was supported by a grant from CORDA.}

\section{References}

1 Slack J. Risks of ischaemic heart disease in familial hyperlipidaemic states. Lancet 1969; ii: 1380-2.

2 Stone NJ, Levy RI, Fredrickson DS, Verter J. Coronary artery disease in 116 kindreds with familial type II hyperlipoproteinemia. Circulation 1974; 49: 476-88.

3 Carvalho ACA, Lees RS. Platelets, intravascular coagulation and fibrinolysis in hyperlipidaemias. Relationship to thromboembolic complications. Acta Med Scand 1979; (suppl 642): 101-12.

4 Carvalho AC, Lees RS, Vaillancourt RA, et al. Intravascular coagulation in hyperlipidaemia. Thromb Res 1976; 8: 843-5.

5 Lowe GDO, Drummond MM, Third JLCH, et al. Increased plasma fibrinogen and platelet aggregates in type II hyperlipoproteinaemia. Thromb Haemost 1979; 42: 1503-7.

6 Meade TW, North WRS, Chakrabarti R, et al. Haemostatic function and cardiovascular death: early results of a prospective study. Lancet 1980; i: 1050-4.

7 Fox K, Selwyn A, Shillingford J. Precordial electrocardiographic mapping after exercise in the diagnosis of coronary artery disease. Am f Cardiol 1979; 43: 541-6.

8 Scandinavian Committee on ECG Classification. The "Minnesota Code" for ECG classification adaptation to CR leads and modification of the code for ECGs recorded during and after exercise. Acta Med Scand 1967; (suppl 481): 1-26.

9 Meade TW, North WRS, Chakrabarti R, Haines AP, Stirling Y. Population-based distributions of haemostatic variables. $\mathrm{Br} \mathrm{Med}$ Bull 1977; 33: 283-8.

10 Fearnley GR, Chakrabarti R. Fibrinolytic treatment of rheumatoid arthritis with phenformin plus ethyloestrenol. Lancet 1966; ii: 757-61.
11 Eggstein M, Kreutz FH. Eine neue Bestimmung der Neutralfette im Blutserum und Gewebe. Klin Wochenschr 1966; 44: 262-7.

12 Huang TC, Chen CP, Wefler V, Raftery A. A stable reagent for the Liebermann-Burchard reaction. Anal Chem 1961; 33: 1405-7.

13 Manual of Laboratory Operations, Lipid Research Clinics Program. Vol. 1. Lipid and lipoprotein analysis. DHEW publication no. $(N I H) 75-628 ; 1974$.

14 Friedewald WT, Levy RI, Fredrickson DS. Estimation of the concentration of low-density lipoprotein cholesterol in plasma, without use of the preparative ultracentrifuge. Clin Chem 1972; 18: 499-502.

15 Sugrue DD, Thompson GR, Oakley CM, Trayner IM, Steiner RE. Contrasting patterns of coronary atherosclerosis in normocholesterolaemic smokers and patients with familial hypercholesterolaemia. $\mathrm{Br} \mathrm{Med} \mathcal{F}$ 1981; 283: 1358-66.

16 Streja D, Steiner G, Kwiterovich PO Jr. Plasma high-density lipoproteins and ischemic heart disease: studies in a large kindred with familial hypercholesterolemia. Ann Intern Med 1978; 89: 871-80.

17 Hirobe K, Matsuzawa Y, Ishikawa K, et al. Coronary artery disease in heterozygous familial hypercholesterolaemia. Atherosclerosis 1982; 44: 201-10.

18 Beaumont J, Jacotot B, Beaumont JL. Ischaemic disease in men and women with familial hypercholesterolaemia and xanthomatosis. A comparative study of genetic and environmental factors in 274 heterozygous cases. Atherosclerosis 1976; 24: 441-50.

19 Heiberg A, Slack J. Family similarities in the age at coronary death in familial hypercholesterolaemia. Br Med F 1977; ii: 493-5.

20 De Wood MA, Spores J, Notske R, et al. Prevalence of total coronary occlusion during the early hours of transmural myocardial infarction. $N$ Engl f Med 1980; 303: 897-902.

21 Dormandy JA, Hoare E, Colley J, et al. Clinical, haemodynamic, rheological and biochemical findings in 126 patients with intermittent claudication. $\mathrm{Br} \mathrm{Med}$ f 1973; iv: 576-81.

22 Lowe GDO, Drummond MM, Lorimer AR, et al. Relation between extent of coronary artery disease and blood viscosity. $\mathrm{Br}$ Med f 1980; 280: 673-4.

23 Velican C, Velican D. The precursors of coronary atherosclerotic plaques in subjects up to 40 years old. Atherosclerosis 1980; 37: 33-46.

24 Smith EB, Staples EM. Haemostatic factors in human aortic intima. Lancet 1981; i: 1171-4.

25 Elkeles RS, Chakrabarti R, Vickers M, Stirling Y, Meade TW. Effect of treatment of hyperlipidaemia on haemostatic variables. Br Med f 1980; ii: 973-4.

26 Srivasta SC, Smith MJ, Dewar HA. The effect of atromid on the fibrinolytic activity of patients with ischaemic heart disease and hypercholesterolaemia. Foumal of Atherosclerosis Research 1963; 3: 640-7.

27 Simpson HCR, Mann JI, Meade TW, Chakrabarti R, Stirling Y, Woolf W. Hypertriglyceridaemia and hypercoagulability. Lancet 1983; i: 786-9.

28 Nestel PJ, Billington R. Effects of probucol on low density lipoprotein removal and high density lipoprotein synthesis. Atherosclerosis 1981; 38: 203-9.

29 Kesaniemi YA, Grundy SM. Turnover of low density lipoproteins during inhibition of cholesterol absorption by neomycin. Arteriosclerosis 1984; 4: 41-8.

30 Brensike JF, Levy RI, Kelsey SF, et al. Effects of therapy with cholestyramine on progression of coronary arteriosclerosis: results of the NHLBI type II coronary intervention study. Circulation 1984; 69: 313-24.

31 Levy RI, Brensike JF, Epstein SE, et al. The influence of changes in lipid values induced by cholestyramine and diet on progression of coronary artery disease: results of the NHLBI type II coronary intervention study. Circulation 1984; 69: 325-37. 